\title{
Job satisfaction of graduates of rural oriented medical students training project in Jiangsu Province, China: a cross-sectional study
}

Wenjun Yan ${ }^{1 *}$, Xiuyin Gao ${ }^{1}$, Wei Wang ${ }^{1}$, Zhengyu Zhou ${ }^{2}$, Chao Zou ${ }^{3}$ and Zhaojun Lu ${ }^{4}$

\begin{abstract}
Background: The Chinese government has worked out the "Rural Oriented Medical Students Training Project" to address physician maldistribution, which attempted to train physicians for rural areas. The present study attempted to evaluate the job satisfaction of the graduates of this project in Jiangsu Province, China.

Methods: Online questionnaires were sent to the graduates of the "Rural Oriented Medical Students Training Project" (group A) and their colleagues, who were rural physicians recruited from different sources (group B). The study was approved by the Ethics Committee of Xuzhou Medical University, and the approval number was 2,018,057. Information on demographic characteristics, work conditions, and self-reported satisfaction was collected to compare the satisfaction differences between the two recruited rural physicians using the Chi-square test and Mann-Whitney $U$ test. Additionally, factors correlated to the satisfaction of group A were assessed using multivariate linear regression. Statistical analysis was performed using SPSS 23.0 (SPSS Inc., Chicago, IL, USA). P $<0.05$ was considered statistically significant.
\end{abstract}

Results: Group A exhibited moderate satisfaction $(2.81 \pm 0.687)$. The satisfaction score from the highest to the lowest was for occupational ecology, life satisfaction, stress, competency, and internal environment. Positive factors related to the satisfaction of group A were area, monthly income, working hours per week, professional title, and post.

Conclusion: The satisfaction of the graduates of the "Rural Oriented Medical Students Training Project" was moderate. Factors related to satisfaction included economic incentives, workload, and professional confidence. Possible solutions for increasing satisfaction should consist of economic support and possible ways to improve the professional identification of these graduates.

Keywords: Graduates of rural oriented medical students training project, rural physicians, Job satisfaction, Survey

\footnotetext{
*Correspondence: baby5744013@163.com

1 Department of General Practice, School of Public Health, Xuzhou

Medical University, Xuzhou 221000, Jiangsu, China

Full list of author information is available at the end of the article
}

\section{Introduction}

Physicians tend to settle in urban areas, creating a worldwide shortage of rural physicians [1]. This further limits the improvement of medical quality in rural areas. In China, traditional medical education produces few rural physicians. One solution to overcome this problem is to train more physicians who identify with and desire to practice among rural communities [2]. Several studies original author(s) and the source, provide a link to the Creative Commons licence, and indicate if changes were made. The images or other third party material in this article are included in the article's Creative Commons licence, unless indicated otherwise in a credit line to the material. If material is not included in the article's Creative Commons licence and your intended use is not permitted by statutory regulation or exceeds the permitted use, you will need to obtain permission directly from the copyright holder. To view a copy of this licence, visit http://creativecommons.org/licenses/by/4.0/. The Creative Commons Public Domain Dedication waiver (http://creativecommons.org/publicdomain/zero/1.0/) applies to the data made available in this article, unless otherwise stated in a credit line to the data. 
referred to rural upbringing and the choice of family medicine as a specialization as factors strongly associated with rural practice [3], suggesting that students with a rural background, rural practice intent, or more excellent service orientation should be recruited into rural practice [4]. Greater rural exposure through either upbringing or education motivates future rural practice and generates a sense of familiarity and community involvement [5].

Numerous countries have initiated solutions and projects to recruit more rural doctors and improve their retention rate. These include "Physician Shortage Area Program (PSAP) [6]" and "Rural Medical Scholars Program (RMSP) [7]" in America, "Rural Clinical School (RCS) Program [8]" in Australia, "Jichi Medical University (JMU) Program [9]" in Japan, "Collaborative Project to Increase Production of Rural Doctors (CPIRD) [10]" in Thailand, and "the Friends of Mosveld Scholarship Scheme (FOMSS) [11]" in South Africa. In China, the plan of "Healthy China 2030" proposed a focus on general practitioners, making it essential to increase the staff in rural and remote areas [12]. The Chinese government introduced the "Rural Oriented Medical Students Training Project [(2010) No. 1198]" in 2010 to deal with the severe shortage of rural physicians. This project attempted to train at least 5000 rural physicians for free annually. According to this policy, the medical colleges in each province recruit and train local rural students annually. Before entering school, the rural students are required to sign contracts with their local bureaus of sanitation. According to the agreement, the graduates must return to their hometown after receiving free medical education and serve as rural physicians for at least 6 years.

Because Jiangsu ranks among the top provinces in terms of gross domestic product (GDP) and per capita GDP in China, it played a leading role in several aspects, including the medical industry. Jiangsu was also one of the earliest provinces to follow the "Rural Oriented Medical Students Training Project". About two hundred of graduates of this project are initiated into the rural medical ecosystem every year.

In order to solve the shortage of doctors in rural areas, on the one hand, rural doctors should be constantly recruited, on the other hand, the retention rate of existing doctors should be ensured. Most of the studies in China and abroad focused on increasing the number of rural doctors. however, rural doctors' retention willing is not clear, questions such as "Are they satisfied with their job as rural physicians?" and "Are they optimistic about being rural physicians?" must be answered and are highly relevant to policymakers. Thus, the present study attempted to evaluate the satisfaction of the graduates of this project in the Jiangsu Province and identify factors associated with higher levels of career satisfaction.

\section{Methods \\ Design}

The present cross-sectional survey was conducted on 507 physicians working in the rural sector from April 2018 to August 24, 2019, under the guidelines of the STROBE statement. A multistage stratified sampling method was employed to select the respondents in the study. Sampling rules were established in the first stage. Jiangsu is an imbalanced province due to the economic level of the 13 cities. The province can be divided into three parts according to financial status, namely northern Jiangsu (per capita GDP $=75,551 \mathrm{RMB}$ ), which includes Xuzhou, Lianyungang, Yancheng, Huaian, and Suqian; central Jiangsu (per capita GDP =123,551 RMB), which includes Yangzhou, Nantong, and Taizhou; and southern Jiangsu (per capita GDP $=167,995 \mathrm{RMB}$ ), which includes Suzhou, Wuxi, Changzhou, Zhenjiang, and Nanjing [13]. Because the retention rate of doctors is related to economic level [14], two cities were selected randomly in northern, central, and southern Jiangsu by drawing lots. Lianyungang and Yancheng were chosen from northern Jiangsu, Yangzhou and Nantong were selected from central Jiangsu, and Nanjing and Changzhou were selected from southern Jiangsu. Our university recruited rural medical students from all 13 cities in Jiangsu, and there was a name list of graduates for each city.

In the second stage, top two graduates for each chosen city were selected from the name list to be liaisons. If the two liaisons in one city worked in the same hospital, skipped the second one until met the one who worked in a different hospital, a total of 12 liaisons were selected. All the liaisons were asked to attend online training and send questionnaires to their rural physician colleagues through their WeChat working group. Team leaders were asked to inform all the respondents of the purpose of this survey before sending questionnaires. To increase the response rate, all respondents received $5 \mathrm{RMB}$ when they handed in their questionnaires. Thus, a series of information was collected. The participants were divided into two groups: group A comprising graduates of the "Rural Oriented Medical Students Training Project" and group B (control group) comprising rural physicians who were not recruited from the project. The survey was conducted on August 15, 2018 for the first time and on August 21, 2019 for the second time. To ensure maximum participation of rural doctors, team leaders connected with doctors who did not respond in WeChat groups in 1 week and asked them to complete the questionnaires. The survey ended on August 24, 2019. 


\section{Questionnaire}

The questionnaire was evaluated and approved by a team of rural health specialists that included experienced doctors and epidemiologists before being sent to the rural physicians. Data on the demographic characteristics and work conditions were collected, whereas self-scale satisfaction was evaluated. All self-evaluation items of satisfaction were classified into five categories by principal component analysis (PCA) (Box 1) comprising internal environment, comfort, competency, stress, and occupational ecology. Questions about satisfaction were self-evaluated using the following fivepoint scale: 1 : dissatisfied; 2 : relatively dissatisfied; 3 : moderate; 4: relatively satisfied; 5 : satisfied. The Cronbach's $\alpha$ coefficient was 0.929 , whereas the KaiserMeyer-Olkin (KMO) was 0.926. The significance of Bartlett's test of sphericity was $P<0.05$. The questionnaire exhibited superior reliability and validity.

The following key question was asked to all participants to evaluate the possibility of quitting their position as a rural physician in the future: "Do you intend to work for your current workplace until you retire?"

\section{Statistical analysis}

All data were exported in Excel form from the questionnaire network (www.wjx.cn). The internal consistency of "satisfaction" was assessed by the Cronbach's $\alpha$ coefficient for the questionnaire. Additionally, the KMO and significance of Bartlett's test of sphericity were reported. The Kolmogorov-Smirnov test was used to test the normal distribution assumption. The Chi-square test was used to test the differences between groups A and B for binary variables, whereas the Mann-Whitney $U$ test was used for rank variables. The six dimensions of satisfaction were presented as mean and standard deviation (SD). The Mann-Whitney U test was used for comparing satisfaction between the two groups. A multivariate linear regression model was used to estimate fixed effects of covariates on each dimension of satisfaction of group A. Results were presented as unstandardized coefficients

Box 1 Satisfaction Scales

\begin{tabular}{|c|c|c|c|c|c|}
\hline & \multicolumn{5}{|l|}{ Composition } \\
\hline & $\begin{array}{l}\text { Internal } \\
\text { Environment }\end{array}$ & Comfort & Competency & Stress & $\begin{array}{l}\text { Occupational } \\
\text { ecology }\end{array}$ \\
\hline How satisfied with the welfare in your hospital? & 0.767 & & & & \\
\hline How satisfied with your employment? & 0.756 & & & & \\
\hline How satisfied with your social insurance? & 0.746 & & & & \\
\hline How satisfied with your income? & 0.669 & & & & \\
\hline How satisfied with your own promotion space? & 0.640 & & & & \\
\hline How satisfied with your own training opportunities? & 0.605 & & & & \\
\hline How satisfied with the relationship with your colleagues? & 0.604 & & & & \\
\hline How satisfied with your work environment? & 0.603 & & & & \\
\hline How satisfied with the balance of income and contribution? & 0.591 & & & & \\
\hline How satisfied with the implementation of policies? & 0.558 & & & & \\
\hline How satisfied with your living convenience? & & 0.694 & & & \\
\hline How satisfied with your job? & & 0.682 & & & \\
\hline How satisfied with your life? & & 0.674 & & & \\
\hline How satisfied with your living conditions? & & 0.591 & & & \\
\hline How satisfied with your career? & & 0.540 & & & \\
\hline How satisfied with your professional skills? & & & 0.853 & & \\
\hline How satisfied with your professional knowledge? & & & 0.848 & & \\
\hline How satisfied with your learning ability? & & & 0.795 & & \\
\hline How satisfied with your motivation? & & & 0.588 & & \\
\hline How satisfied with your Researching capacity? & & & 0.561 & & \\
\hline How satisfied with your clinical workload? & & & & -0.814 & \\
\hline How satisfied with your level of stress at work? & & & & 0.753 & \\
\hline How satisfied with your public health workload? & & & & -0.581 & \\
\hline How satisfied with the doctor-patient relationships & & & & & 0.709 \\
\hline How satisfied with your career reputation? & & & & & 0.630 \\
\hline
\end{tabular}


B and standardized coefficients Beta in addition to significance. Statistical analyses were performed using SPSS 23.0 (SPSS Inc., Chicago, IL, USA). A $P$-value $<0.05$ was considered statistically significant.

\section{Results}

Of the 827 responses received, questionnaires with missing information and misinformation were excluded. Thus, 722 responses were collected (response rate was 87.3\%). Because the first graduates of the "Rural Oriented Medical Students Training Project" had just started working in 2012, there would not be any respondents beyond 40 years. Thus, all respondents above 40 years of age were deleted. The effective respondents were 507 (effective response rate was $61.3 \%$ )..

\section{Demographic characteristics}

Of the 507 participating physicians, 262 (51.7\%) physicians were in group A, whereas 245(48.3\%) physicians were in group B. Of the 245 physicians in group A, $45.8 \%(n=120)$ came from the northern part of Jiangsu, $80.9 \%(n=212)$ were under 30 years old, $55.3 \%$ $(n=145)$ were female, $69.8 \%(n=183)$ were in a relationship, $59.9 \%(n=157)$ earned a monthly income between 3000 and $6000 \mathrm{RMB}, 79.4 \%(n=208)$ were residents, and $85.9 \%(n=225)$ worked as clinicians. As the first class of the "Rural Oriented Medical Students Training Project" just started working in 2012, they were younger and less likely to have a professional title (Table 1).

\section{Work conditions}

The top three work duties of the project graduates were outpatient service $(80.5 \%)$, communication with patients (46.2\%), and file work (39.7\%). Although $55.3 \%$ of graduates attended no more than 60 patients per week, $36.3 \%$ of graduates worked for more than $50 \mathrm{~h}$ per week. Of the total group A participants, 56.5\% wanted further education opportunities. Participants from group A exhibited higher participation in outpatient service $(P=0.016)$ and home visits $(P=0.007)$, higher standardized training rate $(P<0.001)$ (standardized training is regarded as a guarantee of high-quality care in China), higher advanced rank rate $(P<0.001)$, and higher salary in the same rank $(P<0.001)$ than group B (Table 2$)$. In some areas, the recruitment advertisements publicized the possibility of obtaining an advanced rank for graduates of the "Rural Oriented Medical Students Training Project" and higher salaries in the same rank. The data in this investigation concurred with this policy. However, $34.0 \%$ of group A were considering quitting their job..

Table 1 Demographic Characteristics of Group A and Group B

\begin{tabular}{|c|c|c|c|c|c|}
\hline & & Group A (\%) & Group B (\%) & $x^{2}$ or $Z$ & $P$ \\
\hline \multirow[t]{3}{*}{ Area } & Northern JS & $120(45.8)$ & $101(41.2)$ & -1.650 & 0.099 \\
\hline & Central JS & $77(29.4)$ & $63(25.7)$ & & \\
\hline & Southern JS & $65(24.8)$ & $81(33.1)$ & & \\
\hline \multirow[t]{2}{*}{ Age } & $<30$ & 212(80.9) & $106(43.3)$ & 76.76 & $<0.001$ \\
\hline & $30-39$ & $50(19.1)$ & 139(56.7) & & \\
\hline \multirow[t]{2}{*}{ Sex } & Male & $117(44.7)$ & $96(39.2)$ & 1.557 & 0.212 \\
\hline & Female & $145(55.3)$ & 149(60.8) & & \\
\hline \multirow[t]{2}{*}{ Marriage } & Single & $79(30.2)$ & $62(25.3)$ & 1.481 & 0.224 \\
\hline & In a relationship & 183(69.8) & 183(74.7) & & \\
\hline \multirow[t]{3}{*}{ Income Per month (RMB) } & $<3000$ & $63(24.0)$ & $58(23.7)$ & -0.791 & 0.429 \\
\hline & $3000-6000$ & 157(59.9) & $160(65.3)$ & & \\
\hline & $>6000$ & $42(16.1)$ & $27(11.0)$ & & \\
\hline \multirow[t]{4}{*}{ Professional title } & Resident & $208(79.4)$ & 165(67.3) & -3.233 & $<0.001$ \\
\hline & Attending & $54(20.6)$ & $72(29.4)$ & & \\
\hline & Associate chief physician & 0 & $4(1.6)$ & & \\
\hline & Chief physician & 0 & $4(1.6)$ & & \\
\hline \multirow[t]{5}{*}{ Post } & Clinician & 225(85.9) & 204(83.3) & -1.066 & 0.286 \\
\hline & Public health physician & $22(8.4)$ & $12(4.9)$ & & \\
\hline & TCM physician* & $12(4.6)$ & $19(7.8)$ & & \\
\hline & Dentist & $2(0.7)$ & $4(1.6)$ & & \\
\hline & Administrator & $1(0.4)$ & $6(2.4)$ & & \\
\hline
\end{tabular}

*TCM = Traditional Chinese Medicine 
Table 2 Work condition of Group A and Group B

\begin{tabular}{|c|c|c|c|c|c|c|}
\hline & & & Group A (\%) & Group B (\%) & $x^{2}$ or $Z$ & $P$ \\
\hline \multirow[t]{10}{*}{ Major work } & Outpatient service & No & $51(19.5)$ & $70(28.6)$ & 5.777 & 0.016 \\
\hline & & Yes & $211(80.5)$ & $175(71.4)$ & & \\
\hline & File work* & No & $158(60.3)$ & $166(67.8)$ & 3.046 & 0.081 \\
\hline & & Yes & 104(39.7) & $79(32.2)$ & & \\
\hline & Communication & No & $141(53.8)$ & 142(58.0) & 0.881 & 0.348 \\
\hline & & Yes & $121(46.2)$ & 103(42.0) & & \\
\hline & Home visit & No & $169(64.5)$ & $185(75.5)$ & 7.279 & 0.007 \\
\hline & & Yes & $93(35.5)$ & $60(24.5)$ & & \\
\hline & Health education & No & 228(87.0) & $210(85.7)$ & 0.184 & 0.668 \\
\hline & & Yes & $34(13.0)$ & $35(14.3)$ & & \\
\hline \multirow[t]{5}{*}{ Patients per week } & $<30$ & & 87(33.2) & $87(35.5)$ & -1.084 & 0.278 \\
\hline & $30 \sim$ & & $58(22.1)$ & $63(25.7)$ & & \\
\hline & $60 \sim$ & & $42(16.0)$ & $35(14.3)$ & & \\
\hline & $90 \sim$ & & 26(9.9) & $21(8.6)$ & & \\
\hline & $120 \sim$ & & 49(18.7) & $39(16.0)$ & & \\
\hline \multirow[t]{3}{*}{ Work hours per week } & $<40$ & & $59(22.5)$ & $50(20.4)$ & -0.820 & 0.412 \\
\hline & $40 \sim$ & & $108(41.2)$ & $98(40.0)$ & & \\
\hline & $50 \sim$ & & $95(36.3)$ & 97(39.6) & & \\
\hline \multirow[t]{2}{*}{ Standardized training } & & Yes & 207(79.0) & $98(40.0)$ & 80.375 & $<0.001$ \\
\hline & & No & $55(21.0)$ & $147(60.0)$ & & \\
\hline \multirow[t]{2}{*}{ Advanced rank } & & Yes & $61(23.3)$ & $21(8.6)$ & 20.217 & $<0.001$ \\
\hline & & No & $201(76.7)$ & 224(91.4) & & \\
\hline \multirow[t]{2}{*}{ Higher salary in the same rank } & & Yes & 28(10.7) & $4(1.6)$ & 17.550 & $<0.001$ \\
\hline & & No & 234(89.3) & $241(98.4)$ & & \\
\hline \multirow[t]{3}{*}{ Plan in the coming 3 years } & Unchanged & & $66(25.2)$ & $41(16.7)$ & -1.548 & 0.122 \\
\hline & Further education & & $148(56.5)$ & 159(64.9) & & \\
\hline & Not a concern & & 48(18.3) & $45(18.4)$ & & \\
\hline \multirow[t]{3}{*}{ Willing to quit in the future } & Yes & & $89(34.0)$ & $69(28.2)$ & -0.762 & 0.446 \\
\hline & No & & $55(21.0)$ & $64(26.1)$ & & \\
\hline & Not a concern & & $118(45.0)$ & $112(45.7)$ & & \\
\hline
\end{tabular}

*File work: Establish and update health records for rural residents

\section{Satisfaction}

The total satisfaction of both groups was moderate. However, group A reported feeling most satisfied with occupational ecology, followed by life satisfaction, stress, and competency. They reported the least satisfaction with their internal environment (Table 3).

Group A members who practiced in central and southern Jiangsu reported higher satisfaction with their internal environment. Income played a crucial role in each dimension except stress. Moderate working hours per week $(40-50 \mathrm{~h})$ were positively linked with competency, stress, and total satisfaction. On the other hand, excessive working hours per week (approximately $50 \mathrm{~h}$ ) were positively related to stress and negatively linked with the internal environment. Attending doctors were more satisfied with their life satisfaction,
Table 3 Job satisfaction of Group A and Group B

\begin{tabular}{lllll}
\hline Dimension & Group A & Group B & $Z$ & $P$-value \\
\hline Internal environment & $2.81 \pm 0.687$ & $2.87 \pm 0.611$ & -1.231 & 0.218 \\
Life satisfaction & $3.06 \pm 0.699$ & $3.04 \pm 0.628$ & -0.078 & 0.937 \\
Competency & $3.00 \pm 0.654$ & $3.05 \pm 0.563$ & -0.804 & 0.421 \\
Stress & $3.06 \pm 0.463$ & $3.06 \pm 0.426$ & -0.291 & 0.771 \\
Occupational ecology & $3.33 \pm 0.673$ & $3.26 \pm 0.567$ & -1.446 & 0.148 \\
Total satisfaction & $3.05 \pm 0.467$ & $3.06 \pm 0.368$ & -0.162 & 0.872 \\
\hline
\end{tabular}

competency, occupational ecology, and total satisfaction. The post of public health physician was positively correlated with high levels of satisfaction, stress, occupational ecology, and total satisfaction (Table 4). 


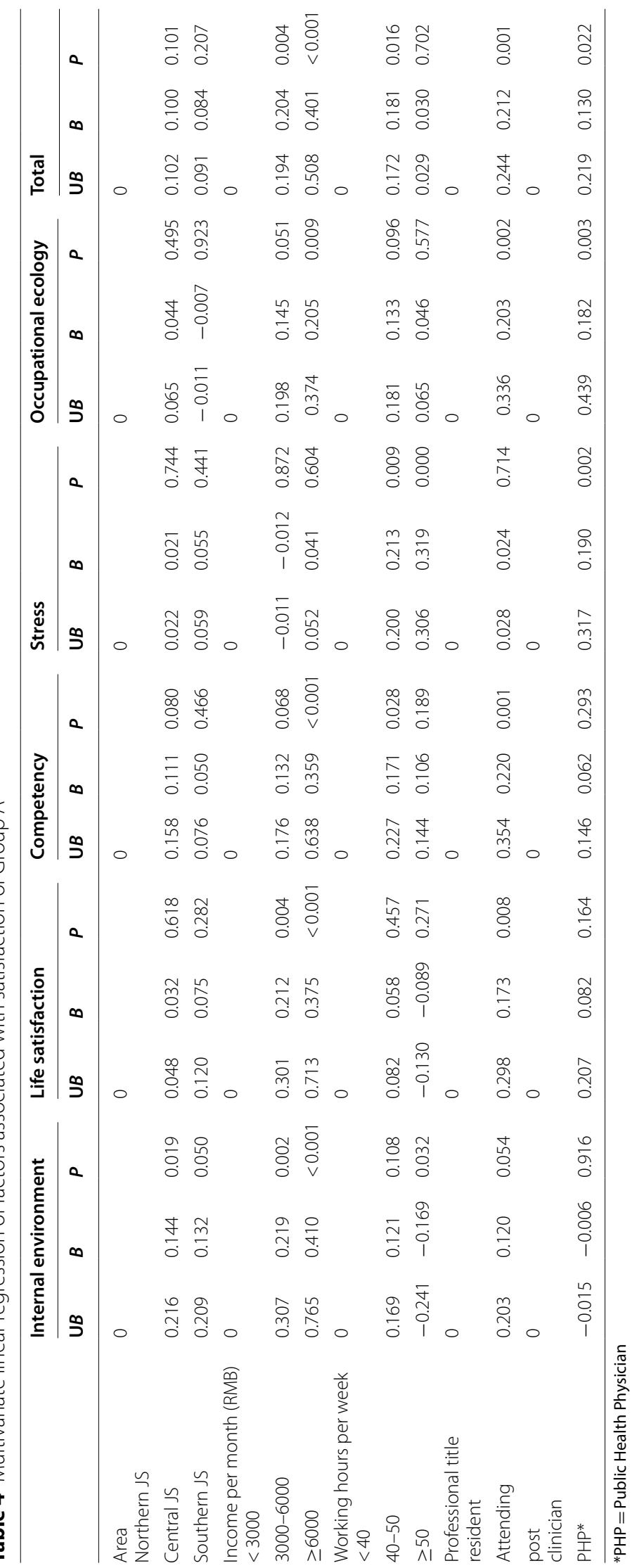




\section{Discussion}

\section{Overall job satisfaction}

The overall job satisfaction of graduates of the "Rural Oriented Medical Students Training Project" was $2.81 \pm 0.687$ in Jiangsu. This score was slightly lower than physicians in western provinces of China [15] and the Shandong province [16], and was much lower than their counterparts in Australia and the US [5, 17]. The present study exhibited that $34.0 \%$ of graduates were considering quitting their job. This was similar to the $34.03 \%$ turnover intention rate reported by a survey for rural doctors in central China [18].

Graduates of the "Rural Oriented Medical Students Training Project" reported the highest levels of satisfaction in occupational ecology $(3.33 \pm 0.673)$ and the lowest levels in the internal environment $(2.81 \pm 0.687)$. This finding was concurrent with that of a Polish study [19], which exhibited a high level of inherent dimension and a low level of personal dimension in similar items.

\section{Factors associated with satisfaction}

Satisfaction is affected by multiple factors. Income can be a major contributor to dissatisfaction. Compared with their counterparts in the United States, Chinese rural doctors have a much lower income with almost similar work hours [20]. In the national range, wages vary widely with the local economic level. The average annual income of rural physicians in Shanghai was 43,400 RMB [21] (3600 RMB per month), whereas $70 \%$ of rural physicians earned less than 2000 RMB per month in the Henan Province [22] The salary of rural doctors in the Jiangxi and Guangxi Provinces was approximately 1500 RMB per month, whereas in the Qinghai Province was approximately 3500 RMB [23]. In the present study, nearly $60 \%$ of rural physicians in Jiangsu earned a monthly income of 3000-6000 RMB, which matched middle- and upperclass salaries nationwide.

The living cost in rural areas is lower than that in urban areas; however, the gap gradually decreases. Additionally, young people in China, including people who worked in rural areas, tend to buy houses downtown. Thus, the commute between town and country also increased the living cost. This could be stressful, especially when the doctors got married or had children. The present study exhibited that an income of 3000-6000 RMB per month was positively linked to the internal environment, life satisfaction, and total satisfaction compared with an income of $<3000 \mathrm{RMB}$, whereas an income of $\geq 6000 \mathrm{RMB}$ per month played positive roles in most dimensions of satisfaction except stress. Low income was directly linked to the retention rates of rural physicians. "Higher salary for the same work" was the promise of some rural hospitals.
This could attract the project graduate physicians when the workplace is remote or the working environment is poor. The graduates in central and southern Jiangsu were more satisfied with the internal environment than their northern counterparts. When we designed this survey, we divided Jiangsu into three areas according to the economic level, which strongly linked to salary, physician well-being, and rural hospital infrastructure. A lack of highly specialized equipment and a lower financing level might pose barriers to providing complex care [19].

Attending doctors were more satisfied with their internal environment, life satisfaction, competency, occupational ecology, and total satisfaction than residents among graduates of the "Rural Oriented Medical Students Training Project". This finding is concurrent with that of a Polish study [19]. Studies exhibited the link between satisfaction, age, and length of employment $[15,16,19,24]$. While professional rank was correlated with age and length of employment, age was not an independent factor of satisfaction, it linked to many factors. This could explain why age did not enter the multiple regression model in the present study. Age, personal qualities, and hard work also play a significant role in attaining a high professional rank. A higher proportion of the project graduates attended outpatient and home visits compared with their counterparts. This explains why attending doctors are more satisfied with competency and occupational ecology. They have their group of patients through years of accumulation, and their patients also recognize their professional services. The critical point for policymakers is to improve the attraction of a rural place and increase the retention rate. "Title promotion" can be used as one of the solutions.

The work hours of rural physicians in Jiangsu were roughly the same as their counterparts in Europe and the US $[19,25]$. According to the present study, 55.3\% of graduates of the "Rural Oriented Medical Students Training Project" serviced no more than 60 patients per week; however, $36.3 \%$ worked for more than $50 \mathrm{~h}$ per week. A positive correlation between moderate work hours per week (40-50h) and high satisfaction on competency, stress, and total satisfaction, higher weekly working hours ( $\geq 50 \mathrm{~h}$ ) were positively linked with total satisfaction and satisfaction on work stress. This finding contradicts with other studies $[15,19]$. One possible explanation for this is that graduates of the "Rural Oriented Medical Students Training Project" comprised a younger population. Thus, they are on a rising period of their career. Working hours accumulate working experience and reflect the value of their job, which also builds professional confidence. Lu et al. [24] mentioned that the retention rate of rural physicians could be affected by recognition of their work. 
Public health physicians (PHP) of the graduates of the "Rural Oriented Medical Students Training Project" were more satisfied with occupational ecology and work stress. In China, PHP is mainly responsible for treating infectious diseases and public health emergencies, healthcare of children aged 0-6years, older adults over 60 years of age, pregnant women, and psychiatric patients [26]. The work content of PHP is relatively fixed. Compared with clinical physicians, PHP exhibited a moderate workload, closer patient-doctor relationships, and a better work reputation.

\section{Suggestions}

Graduates of the "Rural Oriented Medical Students Training Project" exhibited a higher standardized training rate, advanced grade rate, and salary than their peers, meaning that all the promises in the recruitment advertisements have been fulfilled. These policies are crucial in recruiting medical graduates to serve in rural places and should continue to carry forward in the future. But an interesting phenomenon is although the graduates of the "Rural Oriented Medical Students Training Project" showed a "higher salary rate in the same rank" than their peers, their salary is actually no different from that of their peers. The truth is that too few graduates get "higher salary in the same rank". Satisfaction differences by area and income implied that economic incentives, work hours, professional rank, and post all play significant roles in overall work satisfaction, a series of factors that could affect satisfaction or deeply affect the quality of healthcare services. Appropriate solutions are increasing financial support for graduates of the "Rural Oriented Medical Students Training Project". This will enhance their professional development opportunities by setting up training centers in rural places and simplifying the promotion mechanism of professional titles.

\section{Limitation}

Because the "Rural Oriented Medical Students Training Project" has just been implemented for 8 years, the graduates were significantly younger than group B physicians, which might lead to differences in marital status and professional rank. Additionally, the cross-sectional nature of the study precludes causal analysis because it is based only on self-reporting, which could encourage socially desirable answers and does not present a causal relationship between the analyzed variables. Furthermore, because this is an investigation linked by private communication and not an executive order, some of the staff might be left out when sending questionnaires. More solutions should be considered to manage this problem in future research. Moreover, due to the sample size, some meaningful factors might not be identified or some meaningless factors wrongly displayed. These biases can be solved through further research with larger sample size.

\section{Conclusion}

Job satisfaction in graduates of the "Rural Oriented Medical Students Training Project" was moderate. Positive factors related to satisfaction include economic incentives, work hours, professional confidence, and post. Increasing financial aid and developing professional identity should be the key points for health administrations to consider.

\section{Abbreviations \\ GDP: Gross National Product; PCA: Principal Component Analysis; KMO: Kaiser- Meyer-Olkin; SD: Standard Deviation; TCM: Traditional Chinese Medicine; PHP: Public Health Physician.}

\section{Acknowledgements}

We would like to thank the support from the Project of Philosophy and Social Science Research in Colleges and Universities of Jiangsu Province (2018SJA0975).

Additionally, we thank Dr. Kuiyang Zheng and Prof. Guixiang Sun for the sufficient technical support for questionnaire design and survey planning. We also thank all the rural physicians who participated in this survey.

\section{Authors' contributions}

Wenjun Yan designed the study, collected and cleared data, and wrote the main manuscript. Zhaojun Lu and Xiuyin Gao drafted and commented on the paper. Zhengyu Zhou and Chao Zou commented on the paper. Wei Wang designed the study and commented on the paper. All authors have reviewed the manuscript.

\section{Funding}

This study was funded by the Project of Philosophy and Social Science Research in Colleges and Universities of Jiangsu Province (2018SJA0975). The funder had no role in the study design, data collection and analysis, data interpretation, and manuscript writing.

\section{Availability of data and materials}

The datasets used and analyzed during the current study are available from the corresponding author on reasonable request.

\section{Declarations}

Ethics approval and consent to participate

The study was approved by the Ethics Committee of Xuzhou Medical University, and the approval number was 2018057. All methods were performed following the Declaration of Helsinki. The survey data were collected voluntarily and anonymously, without sensitive information about the participants being disclosed. Before the questionnaire, informed consent was obtained from all participants, and detailed information explaining the purpose of the study was provided to them..

\section{Consent for publication}

Not applicable.

\section{Competing interests}

The authors declare that they have no competing interests.

\section{Author details}

${ }^{1}$ Department of General Practice, School of Public Health, Xuzhou Medical University, Xuzhou 221000, Jiangsu, China. ${ }^{2}$ West-City Central Hospital, Lianyungang 222100, Jiangsu, China. ${ }^{3}$ Ma-an Community Health Centre, 
Nanjing 211500, Jiangsu, China. ${ }^{4}$ Second Clinical Medical College, Xuzhou Medical University, Xuzhou 221000, Jiangsu, China.

Received: 4 May 2021 Accepted: 8 December 2021

Published online: 03 January 2022

\section{References}

1. World Health Organization. Increasing access to health workers in remote and rural areas through improved retention; 2010. Available at: http:// www.searo.who.int/nepal/mediacentre/2010_increasing_access_to_ health_workers_in_remote_and_rural_areas.pdf. Accessed March 20, 2016.

2. John RW, James DL, Shannon M, et al. Educating physicians for rural America: validating successes and identifying remaining challenges with the rural medical scholars program. J Rural Health. 2018;34:565-74.

3. William JC, R. Steve F, Craig HZ, David LW. Increasing the rural physician workforce: a potential role for small rural medical school campuses. J Rural Health 32 (2016):254-259.

4. C. Ken S, Jodie J. Validity of medical student questionnaire data in prediction of rural practice choice and its association with service orientation. J Rural Health 31 (2015): 373-381.

5. Brandon V. Analyzing rural versus urban differences in career dissatisfaction and plans to leave among Pennsylvanian physicians. J Rural Health. 2016;32:164-75.

6. Howard KR, James JD, Fred WM, et al. Santana. Retention of Rural Family Physicians After 20-25 Years: Outcomes of a Comprehensive Medical School Rural Program. American Board of Family Medicine. 2003;26(1):24-7.

7. Wheat $J R$, Leeper $J D$, Murphy $S$, et al. Educating physicians for rural America: validating successes and identifying remaining challenges with the rural medical scholars program. J Rural Health, 2018,34(suppl 1):S65-74.

8. Eley DS, Synnott R, Baker PG, et al. A decade of Australian rural clinical school graduates: where are they and why. Rural Remote Health. 2012;12:1937-48.

9. Matsumoto M, Inoue K, Kajii E. Characteristics of medical students with rural origin: implications for selective admission policies. Health Policy. 2008;87(2):194-202.

10. Win T, Rajin A. Rural retention of new medical graduates from the collaborative project to increase production of rural doctors (CPIRD): a 12-year retrospective study. Health Policy Plan. 2017;32:809-15.

11. Ross AJ. Success of a scholarship scheme for rural students. S Afr Med J. 2007;97(11):1087-90.

12. CPC Central Committee, State Council issue "The Plan of Healthy China 2030" Bulletin of the State Council of the People's Republic of China. 2016 (32):5-20.

13. Provincial Bureau of Statistics of Jiangsu. http://tj.jiangsu.gov.cn/2020/ nj02/nj0212.htm

14. Ehsani-Chimeh E, Majdzadeh R, Delavari S, et al. Physicians'retention rate and its effective factors in the Islamic Republic of Iran. East Mediterr Health J. 2018;24(9):830-7.

15. Liu JL, Zhu B, Wu JX, et al. Job satisfaction, work stress, and turnover intentions among rural health workers: a cross-sectional study in 11 western provinces of China. BMC Fam Pract. 2019;20:9.

16. Gu JL, Zhen TM, Song Y, et al. Job satisfaction of certified primary care physicians in rural Shandong Province, China: a cross-sectional study. BMC Health Services Research (2019) 19:75.

17. McGrail M, Russell D, Suttie J, et al. Attracting junior doctors to rural centres: a national study of work-life conditions and satisfaction. Aust J Rural Health. 2019;27:482-8.

18. Shen BJ, Hu LL, You LL, et al. Turnover Intention and Its Influencing Factors among Village Doctors in Central China. Chinese General Practice 2018;21(34):4183-4187. (In Chinese).

19. Alicja D, Juan N, Katarzyna D. Satisfaction of physicians working in polish hospitals - a cross-sectional study. Int J Environ Res Public Health. 2018;15:2640,1-16.

20. Douglas BK, Peter W, Stephen P, et al. Characteristics of young family physician hospitalists. Am Board Family Med. 2018;31(5):680-1.
21. Gao SR, Zhang YM, Liu SS, et al. Cross-sectional investigation on human resources and income status of rural doctors in Shanghai. Chinese Primary Health Care. 2014;28(10):31-3.

22. Gao P, Song JY. Investigation on the income and social security of rural doctors in Henan Province. Health Econ Res. 2019;36(5):8-11.

23. Zhang C, Chen CK, Zhang Z, et al. Study on the current employment situation of targeted admission medical graduates in rural areas. Chinese Journal of Health Policy. 2017;10(5):27-33.

24. LuY, Ju L, Li FF, et al. Analyzing the stability of rural doctor team in Shandong Province in different dimensions. The Chinese Health Service Management. 2018;7:517-20.

25. Huang X, Zuo YL, Tang Q, et al. Studying on the implementation effect of rural - oriented medical education project in Guangxi. The Chinese Health Service Management. 2019;36(3):204-7.

26. Long CX, Tang SF, Feng D, et al. Development and improvement of public health physician system in China. Chin J Public Health. 2019;35(8):937-40.

\section{Publisher's Note}

Springer Nature remains neutral with regard to jurisdictional claims in published maps and institutional affiliations.
Ready to submit your research? Choose BMC and benefit from:

- fast, convenient online submission

- thorough peer review by experienced researchers in your field

- rapid publication on acceptance

- support for research data, including large and complex data types

- gold Open Access which fosters wider collaboration and increased citations

- maximum visibility for your research: over $100 \mathrm{M}$ website views per year

At BMC, research is always in progress.

Learn more biomedcentral.com/submissions 